\title{
Baroreflex sensitivity is reduced in obese normotensive children and adolescents
}

\author{
Zuzana Lazarova, Ingrid Tonhajzerova, Zuzana Trunkvalterova, \\ Andrea Brozmanova, Natasa Honzíková, Kamil Javorka, Mathias Baumert, and \\ Michal Javorka
}

\begin{abstract}
Obesity is associated with autonomic nervous system dysfunction. The aim of the study was to evaluate baroreflex sensitivity, an indicator of autonomic nervous function, in 20 obese children and adolescents in comparison with 20 age- and sex-matched nonobese subjects. All subjects were examined in the supine position over a period of 50 min. Systolic blood pressure (SBP) and RR intervals were monitored continuously. Baroreflex sensitivity was assessed by crossspectral analysis of SBP and RR interval oscillations (BRS index) and SBP and heart rate oscillations (BRSf index) within the low frequency range $(0.04-0.15 \mathrm{~Hz})$. Sensitivity was determined in 3 time intervals of 3 min each to evaluate changes during rest. The BRS index was significantly lower in obese children and adolescents than in the nonobese control group $(p=0.002)$. Significant changes in the BRS index over time $(p=0.004)$ were found only in nonobese subjects. In contrast, the BRSf index increased over time in both groups $(p=0.01)$, and no significant between-group difference was detected. In conclusion, obese children and adolescents show decreased resting baroreflex sensitivity with less variation compared with nonobese subjects. The BRS and BRSf indices appear to be only partially correlated.

Key words: baroreflex sensitivity, obesity, blood pressure, autonomic nervous system, children and adolescents.

Résumé : On associe l'obésité à une dysfonction du système nerveux autonome. La présente étude a eu pour objectif d'évaluer la sensibilité du baroréflexe (SBR), un indicateur de la fonction nerveuse autonome, chez 20 enfants et adolescents obèses et de la comparer à celle de sujets non obèses. Tous les sujets ont été examinés en position couchée pendant une période de 50 minutes. La tension artérielle systolique (TAS) et les intervalles RR ont été mesurés en continu. La SBR a été évaluée au moyen d'une analyse interspectrale des oscillations de la TAS et des intervalles RR (indice de SBR) et des oscillations de la TAS et de la fréquence cardiaque (indice de SBRf), respectivement, dans la plage des basses fréquences $(0,04-0,15 \mathrm{~Hz})$. La SBR a été déterminée trois fois à intervalles de 3 minutes pour évaluer les modifications au repos. L'indice de SBR a diminué de façon appréciable chez les enfants et les adolescents obèses comparativement à ce qui a été observé chez le groupe témoin non obèse $(p=0,002)$. Seuls les sujets non obèses ont présenté des modifications significatives de l'indice de SBR avec le temps $(p=0,004)$. À l'opposé, l'indice de SBRf a augmenté avec le temps chez les deux groupes $(p=0,01)$, mais aucune différence significative inter-groupe n'a été détectée. En conclusion, il y a moins de variation dans la diminution de la sensibilité baroréflexe au repos chez les enfants et les adolescents obèses que chez les sujets non obèses. Il existe peu de corrélation entre les indices de SBR et de SBRf.
\end{abstract}

Mots-clés : sensibilité baroréflexe, obésité, tension artérielle, système nerveux autonome, enfants et adolescents.

[Traduit par la Rédaction]

\section{Introduction}

The baroreflex plays an important role in blood pressure regulation. Baroreceptors affect not only the control of resistance vessels and venous capacity, but also heart rate. The baroreflex is important for maintaining physiological

Received 28 May 2008. Accepted 27 February 2009. Published on the NRC Research Press Web site at cjpp.nrc.ca on 6 July 2009.

Z. Lazarova, ${ }^{1}$ I. Tonhajzerova, $Z$. Trunkvalterova, A. Brozmanova, K. Javorka, and M. Javorka. Department of Physiology, Jessenius Faculty of Medicine, Comenius University, Mala Hora 4, 03754 Martin, Slovak Republic. N. Honzíková. Department of Physiology, Faculty of Medicine, Masaryk University, Brno, Czech Republic.

M. Baumert. School of Paediatrics and Reproductive Health, The University of Adelaide, SA 5005, Australia.

${ }^{1}$ Corresponding author (e-mail: lazarova@jfmed.uniba.sk). blood pressure (BP) levels and organ perfusion under different conditions, aiming at both the short-term buffering of changes in arterial blood pressure and the long-term setting of pressure levels (Kardos et al. 2001; Honzíková et al. 2003). Decreased baroreflex sensitivity is a negative prognostic factor of cardiovascular morbidity and sudden cardiac death (La Rovere et al. 1998; Honzíková et al. 2000a, $2000 b)$.

Over the past two decades, one particular aspect of baroreflex control has gained increasing attention, that of the chronotropic heart response to changes in systolic blood pressure (SBP). The baroreflex sensitivity index (the BRS index) is usually expressed as a function of the RR interval on systolic BP, in milliseconds per millimetre of mercury (ms/mm Hg) (Persson et al. 2001), although several studies have quantified baroreflex sensitivity as a function of heart rate on systolic BP (the BRSf index) in millihertz per millimetre of mercury ( $\mathrm{mHz} / \mathrm{mm} \mathrm{Hg}$ ) (Al-Kubati et al. 1997; Za- 
vodna et al. 2006). The BRSf index is less dependent on the mean RR interval than is the BRS index and was proposed for baroreflex assessment during childhood, a stage in which the mean heart rate normally reduces with age (Zavodna et al. 2006).

Baroreflex sensitivity is typically determined either during manoeuvres that induce marked BP changes, or during steady-state conditions by measuring spontaneous BP oscillations (La Rovere et al. 1998; Laitinen et al. 1998). Sensitivity estimation techniques based on spontaneous BP and heart rate variability were developed in the time and frequency domains. Data from several studies indicate that the various techniques provide comparable, but not identical, information on baroreflex sensitivity (Persson et al. 2001).

Different factors influence baroreflex sensitivity in the normal population, including sex, age, level of physical activity, mean BP, heart rate, body mass index (BMI), mechanical properties of arteries, and plasma levels of glucose and insulin (Parati et al. 1988; Laederach-Hofmann et al. 2000; Kardos et al. 2001; Honzíková et al. 2006a). In adults, decreased baroreflex sensitivity was found in various pathological conditions, including diabetes mellitus (Frattola et al. 1997; Lefrandt et al. 1999), hypertension (Gribbin et al. 1971; Lábrová et al. 2005) and obesity (Grassi et al. 1995; Alvarez et al. 2005). The decrease in baroreflex sensitivity may be caused by autonomic nervous system (ANS) dysfunction (Spraul et al. 1994; Chapleau et al. 1995; Miller et al. 1999), and (or) by changes in the mechanical properties of the arterial wall (Tanaka et al. 2001; Honzíková et al. 2006a).

Obesity causes a wide spectrum of subsequent health problems, including cardiovascular, metabolic, orthopedic, gastrointestinal, pulmonary, and psychosocial complications (Laederach-Hofmann et al. 2000). Obesity is associated with an increased mortality due to cardiovascular complications (Drenick et al. 1980). Therefore, there is increasing interest in the relationship between obesity and early cardiovascular complications during childhood (Tonhajzerova et al. 2006). Previous studies in adult obese patients (Spraul et al. 1994; Kardos et al. 2001; Honzíková et al. 2006b; Krontorádová et al. 2008) indicate a relationship between obesity and reduced baroreflex sensitivity. It is not currently well established, however, whether obesity in the early years of life has already had an adverse effect on baroreflex control. The aim of this study was therefore to compare baroreflex sensitivity during rest in obese normotensive children and adolescents with that of an age and sexmatched nonobese control group.

\section{Materials and methods}

\section{Subjects}

Forty subjects were examined: 20 obese (12 girls, 8 boys; mean age $14.9 \pm 2.1$ years (range $12-18$ years), mean BMI $32.5 \pm 0.9 \mathrm{~kg} / \mathrm{m}^{2}$ ) and 20 nonobese age and sex-matched normotensive children and adolescents (BMI $20.6 \pm 0.3 \mathrm{~kg} / \mathrm{m}^{2}$ ). Obesity was diagnosed according to recommendations of the International Obesity Task Force (Lobstein et al. 2004). All subjects were nonsmokers without cardiovascular or endocrine diseases or diabetes mellitus. All subjects and their parents were informed about the purpose and pro- tocol of the study. Written informed consent was provided before the examination. Subjects were instructed not to use substances influencing the cardiovascular system (caffeine, alcohol) for $24 \mathrm{~h}$ before the examination. The study was approved by the ethics committee of the Jessenius Faculty of Medicine, Comenius University.

\section{Protocol}

All subjects were examined from 08:30 to 12:00 while they rested in the supine position on a bed in a quiet room with standard temperature $\left(23{ }^{\circ} \mathrm{C}\right)$ and minimal arousal stimuli. A thoracic belt with ECG electrodes and the finger cuff of the Finapres device were applied after a stabilization period of $15 \mathrm{~min}$. The subjects remained in the supine position for the subsequent $50 \mathrm{~min}$ of continuous cardiovascular parameters recording. The measurements were taken during spontaneous breathing and the subjects were instructed to minimize voluntary movements as much as possible. Consecutive RR intervals were provided by the ECG system (Cardiofax ECG-9620M, Nihon Kohden, Tokyo, Japan). SBP was continuously and noninvasively monitored by the Finapres (Ohmeda 2300, USA). ECG and continuous blood pressure signals were transferred to a PC using an analogdigital converter (Advantech PCL 711, Taiwan) at a sampling rate of $500 \mathrm{~Hz}$.

\section{Baroreflex sensitivity}

Baroreflex sensitivity was determined 3 times during intervals of 3 min each: T1 (starting from the 15th min of recording), T2 (starting from the 30th min), and T3 (starting from the 45th min). The values of SBP were derived from the local maxima of the continuous blood pressure signal. We obtained sequences of beat-to-beat SBP values and the corresponding RR intervals (derived from ECG recording). Equidistant time sequences for both signals were obtained by interpolating neighbouring SBP and RR interval values linearly at a sampling interval of $250 \mathrm{~ms}$. Linear trends were removed from both signals, using the least-squares approximation method.

The BRS index was assessed by the cross-spectral method according to Bendat and Piersol (1971). Our method was first described in Honzíková et al. (1992) and in detail in Zavodna et al. (2006). It comprises the following steps:

First, the autocorrelation function of the SBP sequence and the cross-correlation function between SBP and RR sequences were calculated. The power spectrum of the SBP time sequence was then calculated as the spectrum of autocorrelation function of the SBP sequence. The cross-spectrum of the SBP and RR sequences was calculated accordingly from the cross-correlation function of the SBP and RR sequences. A Hanning window was used to avoid spectral leakage. Subsequently, the coherence function was calculated. The baroreflex gain was then calculated as the quotient between the cross-spectrum of SBP and RR intervals and the power spectrum of SBP.

The BRS index was determined in the frequency range of $0.04-0.15 \mathrm{~Hz}$ at the point of highest coherence. BRS values were taken into account only if the coherence was higher than 0.5. If more than 1 peak was present within this frequency range, the sum of values of coherence was normal- 
ized to 1 and the corresponding BRS values were weighted according to the actual normalized coherence value.

It was shown that adjusting the BRS index for the mean RR interval is useful especially in the case of considerable differences in mean heart rate (Abrahamsson et al. 2003; Wesseling 2003; Zavodna et al. 2006). Abrahamsson et al. (2003) proposed to standardize the patient's BRS index to a fixed heart rate of 60 beats/min by using the logarithm of the BRS index and a linear regression function. This method does not seem to be ideal because linearity between $\log (\mathrm{BRS})$ and the heart rate occurs typically only in the heart rate range of $80-120$ beats/min (Wesseling 2003). On the other hand, baroreflex sensitivity calculated on the basis of instantaneous heart rate- the BRSf index-yielded a decrease in baroreflex sensitivity in subjects aged between 11 and 20 years, an age at which the vagal tone typically increases, heart rate decreases, and BRS index is unchanged (Zavodna et al. 2006). Therefore, we also calculated the value of the baroreflex gain factor at a frequency of $0.1 \mathrm{~Hz}$ in a similar way, using spectral analysis of instantaneous values of heart rate and SBP. Thus we obtained the BRSf index $(\mathrm{mHz} / \mathrm{mm} \mathrm{Hg})$.

During the recording, the breathing rate was continuously monitored by a plethysmographic device (RespiTrace 200, NIMS, USA). In all subjects the breathing rate was higher than 12 breaths/min (i.e., greater than $0.2 \mathrm{~Hz}$ ) throughout the measurement. We therefore suggest that the lowfrequency band (below $0.15 \mathrm{~Hz}$ ) was not contaminated by respiration-related fluctuations.

\section{Anthropometric measurements}

Measurements of weight, height, and waist and hip circumferences were performed after the cardiovascular parameters were recorded. The waist-to-hip ratio (WHR) was computed as a measure of fat distribution. The percentage of body fat was estimated on the basis of bioelectrical impedance analysis (Omron BF-302, Japan).

\section{Statistical analysis}

Two-way ANOVA with a grouping factor of obese versus control and a repeated-measures factor of time interval (T1T3) was used for statistical analyses. The normal distribution of the variables was verified with the Lilliefors test. Furthermore, we investigated the relationship between the two baroreflex sensitivity indices and anthropometric measures using Pearson's correlation coefficients. Descriptive statistics are presented as means \pm SE. Values of $p<0.05$ were considered statistically significant in inferential statistics.

\section{Results}

\section{Basic characteristics of subjects}

As per study design, obese children had a significantly higher body mass index $(p<0.001)$, waist-hip ratio $(p<$ $0.001)$ and percentage of body fat $(p<0.001)$ compared with healthy controls. Although all subjects were normotensive, the between-group comparison showed significantly increased SBP levels in the obese group and shortened mean RR intervals, that is, higher heart rates (Table 1).

No significant time effects (changes between T1 and T3) were found on the mean RR interval length and mean heart rate (for mean RR interval length, the effect of time was $p=$ 0.65 and the time versus group (control, obese) interaction was $p=0.59$; for mean heart rate, the effect of time was $p=0.42$ and the time versus group interaction was $p=0.51$ (by two-way ANOVA)). Similarly, mean SBP did not change significantly during $50 \mathrm{~min}$ of recording (by two-way ANOVA, the effect of time was $p=0.29$ and the time versus group interaction was $p=0.29$ ).

\section{Baroreflex sensitivity-the BRS index}

The BRS index was significantly reduced in young obese subjects compared with nonobese controls (ANOVA, $p=$ 0.002) (Fig. 1). In nonobese subjects, the BRS index increased significantly with progressing recording time (50 min) (ANOVA, $p=0.004$ ). In contrast, the BRS index remained stable in obese subjects throughout the recording (ANOVA, the time vs. group interaction $p=0.04$ ) (Fig. 1).

Analysis of covariance (ANCOVA) with the parameter mean RR interval length as a covariate showed results similar to ANOVA. No significant effect of covariate was found.

\section{Baroreflex sensitivity-the BRSf index}

The BRSf index increased significantly throughout the recording in both obese and nonobese subjects (ANOVA: factor time, $p=0.01$ ) (Fig. 2). However, no significant group differences in the BRSf index and its time course were found (ANOVA: factor group, $p=0.13$; interaction group $\times$ time: $p=0.74$ ) (Fig. 2).

Similarly to the BRS index, we also performed analysis of covariance (ANCOVA) with mean RR interval length. No significant effect of covariate was found, indicating a lack of correlation between mean RR interval length and the BRSf index.

\section{Correlations between anthropometric indices and BRS}

We performed correlation analysis between the BRS and BRSf indices obtained from the T3 interval and anthropometric measures (BMI, WHR, and percentage fat) in the obese group. The T3 interval was chosen as it showed the most pronounced between-group differences in the BRS.

BMI was negatively correlated with the BRS index $(r=-0.51, p=0.03)$, but not with BRSf. Neither WHR nor the percentage fat significantly correlated with the BRS and BRSf indices (Table 2).

\section{Discussion}

The main finding of our study is a decreased BRS index in obese normotensive children and adolescents in comparison with control subjects. Further, baroreflex sensitivity varies in the supine position over time: in the nonobese subjects, the BRS index increased continuously, whereas in the obese group there was no significant change.

\section{Baroreflex sensitivity and obesity in children and adolescents}

There is increasing evidence of an inverse correlation between baroreflex sensitivity and percentage of body fat in adults (Laederach-Hofmann et al. 2000; Kardos et al. 2001) but the knowledge regarding this relation in children and adolescents is incomplete. Only a few studies have assessed 
Table 1. Anthropometric characteristics of the obese and nonobese children and adolescents enrolled in the study.

\begin{tabular}{llll}
\hline & Obese group $(n=20)$ & Nonobese group $(n=20)$ & $p$ value \\
\hline Age, years & $14.9 \pm 2.1$ & $15.1 \pm 1.9$ & 0.77 \\
BMI, kg/m & $32.48 \pm 0.96$ & $20.59 \pm 0.34$ & $<0.001$ \\
WHR & $0.86 \pm 0.02$ & $0.75 \pm 0.01$ & $<0.001$ \\
Fat, \% & $37.1 \pm 0.6$ & $20.9 \pm 0.9$ & $<0.001$ \\
Mean RR interval, ms & $835 \pm 27$ & $914 \pm 26$ & 0.02 \\
SBP, mm Hg & $128 \pm 3$ & $116 \pm 3$ & 0.03 \\
DBP, mm Hg & $61 \pm 3$ & $58 \pm 3$ & 0.18 \\
\hline
\end{tabular}

Note: BMI, body mass index; WHR, waist-hip ratio; SBP, systolic blood pressure; DBP, diastolic blood pressure. Values are means $\pm \mathrm{SE}$.

Fig. 1. The BRS index $(\mathrm{ms} / \mathrm{mm} \mathrm{Hg})$ as a measure of baroreflex sensitivity in obese and nonobese subjects in the supine position quantified during rest over 3 time intervals (T1-T3). The bars and whiskers indicate means and SE, respectively. BRS index is significantly lower in obese subjects. Results of ANOVA: factor group, $p=0.002$; factor time, $p=0.004$; interaction groups $\mathrm{x}$ time, $p=$ 0.04 . T1 corresponds to the first time interval, from the 15 th to the 18th min; T2 to the second time interval, from the 30th to the 33rd min; and T3 to the third time interval, from the 45 th to the 48th $\min$.

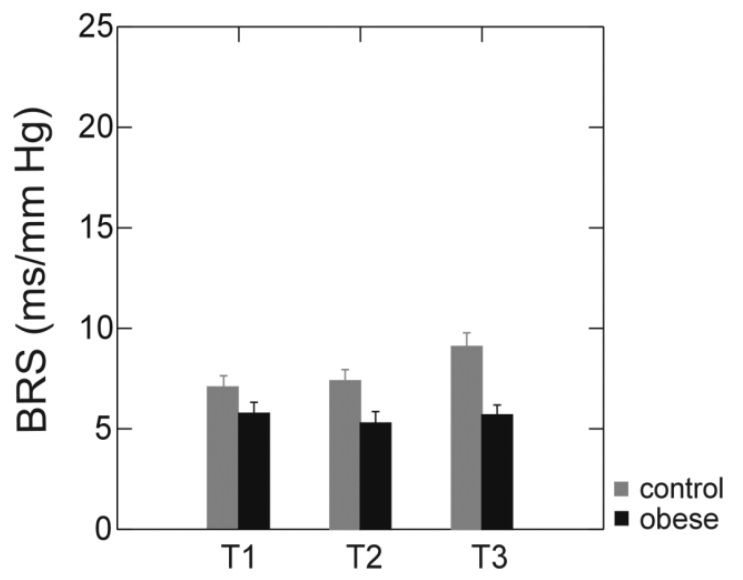

baroreflex sensitivity in obese children. Our results confirm the findings of Dietrich et al. (2006) and Honzíková et al. (2006b), who described a negative correlation between the BRS index and BMI in obese children. Honzíková et al. (2006b) examined baroreflex sensitivity in children, adolescents, and young adults with essential and white-coat hypertension, and we have extended their findings by investigating normotensive obese subjects. Our study provides evidence that obesity per se (even in young obese subjects) can lead to baroreflex impairment, as indicated by significant difference between obese and nonobese groups. Correlation analysis revealed a significant association between the severity of the obesity and the baroreflex impairment in our group of obese patients (i.e., a significant negative correlation between the BRS index and BMI).

\section{Baroreflex sensitivity reduction-possible mechanisms}

There are multiple mechanisms whereby obesity can affect baroreflex sensitivity, but they are incompletely understood. Given that a decrease in baroreflex sensitivity has
Fig. 2. The BRSf index $(\mathrm{mHz} / \mathrm{mm} \mathrm{Hg})$ as a measure of baroreflex sensitivity in obese and nonobese subjects in the supine position quantified during rest over 3 time intervals (T1-T3). The bars and whiskers indicate means and SE, respectively. BRSf index increases significantly over time in both groups. No significant betweengroup difference was detected. Results of ANOVA: factor group, $p=0.13$; factor time, $p=0.01$; interaction group $\times$ time, $p=0.74$. Time intervals as in Fig. 1.

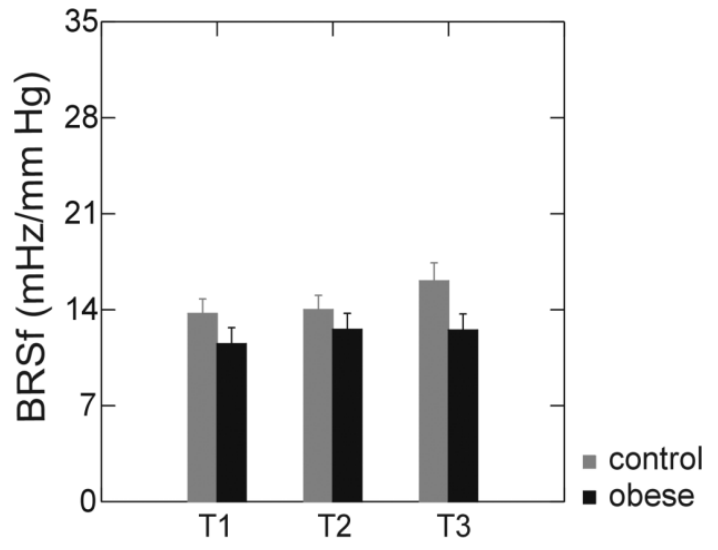

Table 2. Pearson's correlation coefficients computed between 2 indices of baroreflex sensitivity and anthropometric characteristics in the obese group.

\begin{tabular}{lll}
\hline & BRS index & BRSf index \\
\hline BMI, $\mathrm{kg} / \mathrm{m}^{2}$ & $-0.51^{*}$ & -0.38 \\
WHR & -0.05 & 0.17 \\
Fat, \% & -0.14 & 0.23 \\
\hline
\end{tabular}

Note: BMI, body mass index; WHR, waist-hip ratio. *, significant correlation at $p<0.05$.

been associated with an increase in the thickness of the carotid wall (Zanchetti et al. 1998; Honzíková et al. 2006a) and furthermore, that increased carotid intima-media thickness and stiffness have been found in obese children (Woo et al. 2002; Iannuzzi et al. 2004), increased carotid stiffness may be one potential mechanism responsible for the reduction in baroreflex sensitivity observed in the obese group.

Because of the reduced insulin sensitivity (Rocchini et al. 1992) and increased plasma renin activity (Tuck et al. 1981) in obese patients, another mechanism responsible for reduced baroreflex sensitivity may be sympathetic overactivity caused by an increase in plasma levels of insulin and (or) angiotensin II (Chapleau et al. 1995; Miller et al. 1999). Fur- 
ther, the leptin secretion of adipose tissue, which also increases sympathetic activity (Matsumoto et al. 2003), is thought to reduce baroreflex sensitivity (Egan 2003) in obese adults with essential hypertension (Narkiewicz et al. 1999; Grassi et al. 2004).

Previous studies in adults have shown that obesity related sympathetic overactivity is associated with baroreflex impairment (Spraul et al. 1994; Grassi et al. 2004). On the other hand, the reduction in afferent restraint on the vasomotor center could be an important factor mediating sympathetic activation in obese subjects. Hence, the relationship between baroreflex sensitivity and sympathetic overactivity may be bidirectional. Because sympathetic and parasympathetic systems act on heart function concomitantly, their effects are not additive algebraically, but complex interactions occur. Such interaction may be mediated either prejunctionally or postjunctionally with respect to the neuroeffector junction (Levy 1997).

It is necessary to point out the general presence of presynaptic receptors sensitive to neuropeptides and other chemical signals released from adjacent nerve terminals that either facilitate or inhibit the release of a transmitter (Langer 2008). The hypothesis that neurally released neuropeptide $Y$ (NPY) mediates sympathetically evoked inhibition of vagal effects on heart rate was supported by experiments in dogs. NPY released together with norepinephrine on sympathetic activation mediated the sympathetically evoked inhibition of vagal effects for several tens of minutes (Warner et al. 1991). This effect may be responsible for the long-term decrease in vagal reactivity in obese subjects during $50 \mathrm{~min}$ of rest in our study. Gradual vagal activation due to previously lower sympathetic activity may explain the observed increase of baroreflex sensitivity during supine rest in control subjects. Because no significant changes in mean duration of the RR interval or mean heart rate were found in either group, the mechanism causing the increased sensitivity during supine rest in the control group is unclear.

It was also shown that the effect of antecedent sympathetic stimulation on chronotropic response to vagal stimulation can also be mediated postjunctionally (Yang et al. 1994). It is beyond the scope of this study to review all factors that could be taken into account, explaining how sympathetic activation could lead to the long-term reduction in baroreflex sensitivity.

From this point of view, it is also important to note that baroreflex sensitivity affects sympathetic activity. Prolonged activation of the baroreflex abolishes obesity-induced hypertension and inhibits renal sympathetic nerve activity (Lohmeier et al. 2000, 2005, 2007).

Taken together, we suggest that the ANS imbalance (impairment of parasympathetic nervous system activity and (or) sympathetic overactivity) may play an important role in the BRS index reduction observed in our group of young obese patients. Because the magnitude of SBP oscillations in the LF band is regarded as an index of sympathetic control, whereas the magnitude of RR interval oscillations in the high frequency (HF) $0.15-0.4 \mathrm{~Hz}$ band is used as an index of parasympathetic activity (Takalo et al. 1994), we also performed SBP and heart rate variability analyses (results not shown). No significant differences in the magnitude of LF blood pressure oscillations and a tendency towards lower
HF in RR interval signal were found in obese subjects compared with the control group (the only significant difference in HF power was found in the $\mathrm{T} 2$ interval). In addition, we observed mildly elevated heart rate in the obese group (see Table 1). These results support the concept of parasympathetic nervous system activity reduction in obese children, as previously shown by Nagai et al. (2003).

Decreased physical activity, more likely in obese children, may also be one of the reasons for reduction in baroreflex sensitivity. There is a large body of evidence, showing that regular moderate exercise increases parasympathetic heart rate modulations and elevates baroreflex sensitivity (Mancia et al. 1978, Honzíková et al. 1997).

\section{BRS index versus BRSf index}

Usually, BRS is computed from RR interval changes (in $\mathrm{ms}$ ) elicited by the oscillations in SBP (in $\mathrm{mm} \mathrm{Hg}$ ) - termed the BRS index. Al-Kubati et al. (1997) proposed a new index, called BRSf, which expresses the relation between heart rate (in $\mathrm{mHz}$ ) and the magnitude of blood pressure oscillations. In accordance with previous studies (Honzíková et al. 2003; Zavodna et al. 2006), we found that the BRS and BRSf indices were only partially correlated. Although both BRS and BRSf indices are derived from $0.1 \mathrm{~Hz}$ oscillations and are mathematically interrelated, they are not equivalent. The mathematical relationship between RR interval and heart rate is nonlinear, causing a partially independent behaviour of both indices. The BRS index generally depends on the mean RR interval, whereas BRSf does not (Al-Kubati et al. 1997). Thus the BRS index, baroreflex sensitivity expressed in milliseconds per millimetre of mercury $(\mathrm{ms} / \mathrm{mm} \mathrm{Hg})$, appears to be a better indicator of the sudden death risk in patients after acute myocardial infarction than the BRSf index, baroreflex sensitivity expressed in millihertz per millimetre of mercury $(\mathrm{mHz} / \mathrm{mm} \mathrm{Hg}$ ) (Al-Kubati et al. 1997). In contrast, Zavodna et al. (2006) concluded that the BRSf index better reflects the ontogenetic changes of the baroreflex sensitivity. Therefore, the parallel assessment of both indices appears to be preferable for the detection of cardiovascular dysregulation.

\section{BRS index versus mean $R R$ interval length}

The mean RR interval was significantly shorter in obese subjects than in controls throughout the $50 \mathrm{~min}$ of recording and this did not change significantly in any group with time. In contrast to previous observations (Van Vliet et al. 1995; Honzíková et al. 1997; Zavodna et al. 2006), no significant correlation between mean RR interval duration and BRS index was found in our study. The reasons for this discrepancy remain speculative.

First, there was a relatively large age range in both groups, and age differences may play a role in this relationship (Zavodna et al. 2006). Second, the lack of correlation may be related to the emotional state (Honzíková et al. 1996): a slight emotional activation produces a decrease in BRS index that is not accompanied by changes in heart rate and blood pressure. On the other hand, lower baroreflex sensitivity and higher blood pressure were found in obese subjects compared with controls over the entire period of 50 min resting in supine position. We can only speculate that a basal sympathetic overactivity counteracted an increase of baroreflex sensitivity in time in obese patients. 


\section{Conclusion}

In conclusion, baroreflex sensitivity is significantly reduced in obese children and adolescents compared with nonobese controls. The quantification of baroreflex sensitivity during rest and its change over time provide information on cardiovascular dysregulation in young normotensive obese subjects. Reduced baroreflex sensitivity may be indicative of future development of cardiovascular disease in obese children and adolescents. Because weight loss improves cardiovagal baroreflex functioning in obese patients (Alvarez et al. 2005), early weight reduction appears to be of utmost importance even in obese children and adolescents.

\section{Acknowledgements}

This study was supported by the Centre of Excellence for Perinatological Research project grant 26220120016; VEGA grant 1/0064/08; MVTS grant CR/SR/UK2/08; European Social Fund Project SOP LZ 2005/NP1-027; and grant MSM 0021622402 from the Ministry of Education, Youth and Sports of the Czech Republic.

\section{References}

Abrahamsson, C., Ahlund, C., Nordlander, M., and Lind, L. 2003. A method for heart rate-corrected estimation of baroreflex sensitivity. J. Hypertens. 21(11): 2133-2140. doi:10.1097/00004872200311000-00023. PMID:14597857.

Al-Kubati, M.A.A., Fiser, B., and Siegelová, J. 1997. Baroreflex sensitivity during psychological stress. Physiol. Res. 46(1): 2733. PMID:9728518.

Alvarez, G.E., Davy, B.M., Ballard, T.P., Beske, S.D., and Davy, K.P. 2005. Weight loss increases cardiovagal baroreflex function in obese young and older men. Am. J. Physiol. 289(4): E665E669.

Bendat, J.S., and Piersol, A.G. 1971. Random data: analysis and measurement procedures. John Wiley and Sons, New York.

Chapleau, M.W., Cunningham, J.T., Sullivan, M.J., Wachtel, R.E., and Abboud, F.M. 1995. Structural versus functional modulation of the arterial baroreflex. Hypertension, 26(2): 341-347. PMID: 7543454.

Dietrich, A., Riese, H., van Roon, A.M., van Engelen, K., Ormel, J., Neeleman, J., and Rosmalen, J.G. 2006. Spontaneous baroreflex sensitivity in (pre)adolescents. J. Hypertens. 24(2): 345352. doi:10.1097/01.hjh.0000200517.27356.47. PMID:16508583.

Drenick, E.J., Bale, G.S., Seltzer, F., and Johnson, D.G. 1980. Excessive mortality and causes of death in morbidly obese men. JAMA, 243(5): 443-445. doi:10.1001/jama.243.5.443. PMID: 7351764.

Egan, B.M. 2003. Insulin resistance and the sympathetic nervous system. Curr. Hypertens. Rep. 5(3): 247-254. doi:10.1007/ s11906-003-0028-7. PMID: 12724058.

Frattola, A., Parati, G., Gamba, P., Paleari, F., Mauri, G., Di Rienzo, M., et al. 1997. Time and frequency domain estimates of spontaneous baroreflex sensitivity provide early detection of autonomic dysfunction in diabetes mellitus. Diabetologia, 40(12): 1470-1475. doi:10.1007/s001250050851. PMID: 9447956.

Grassi, G., Seravalle, G., Cattaneo, B.M., Bolla, G.B., Lanfranchi, A., Colombo, M., et al. 1995. Sympathetic activation in obese normotensive subjects. Hypertension, 25(4 Pt 1): 560-563. PMID:7721398.

Grassi, G., Dell'Oro, R., Facchini, A., Quarti Trevano, F., Bolla, G.B., and Mancia, G. 2004. Effect of central and peripheral body fat distribution on sympathetic and baroreflex function in obese normotensives. J. Hypertens. 22(12): 2363-2369. doi:10. 1097/00004872-200412000-00019. PMID:15614031.

Gribbin, B., Pickering, T.G., Sleight, P., and Peto, R. 1971. Effect of age and high blood pressure on baroreflex sensitivity in man. Circ. Res. 29(4): 424-431. PMID:5110922.

Honzíková, N., Fiser, B., and Honzík, J. 1992. Noninvasive determination of baroreflex sensitivity in man by means of spectral analysis. Physiol. Res. 41(1): 31-37. PMID:1610775.

Honzíková, N., Rybkova, I., and Honzik, J.M. 1996. Baroreflex sensitivity, heart rate and blood pressure during mental load and emotional activation. Homeostasis, 37: 72-76.

Honzíková, N., Semrad, B., Fiser, B., and Labrova, R. 1997. Heart rate variability and baroreflex sensitivity in healthy subjects and in postinfarction patients treated by thrombolysis. Exp. Clin. Cardiol. 2(1): 69-72.

Honzíková, N., Fiser, B., and Semrad, B. 2000a. Critical value of baroreflex sensitivity determined by spectral analysis in risk stratification after myocardial infarction. Pacing Clin. Electrophysiol. 23(11 Pt 2): 1965-1967. PMID:11139968.

Honzíková, N., Semrád, B., Fiser, B., and Lábrová, R. 2000b. Baroreflex sensitivity determined by spectral method and heart rate variability, and two-years mortality in patients after myocardial infarction. Physiol. Res. 49(6): 643-650. PMID:11252529.

Honzíková, N., Krticka, A., Nováková, Z., and Závodná, E. 2003. A dampening effect of pulse interval variability on blood pressure variations with respect to primary variability in blood pressure during exercise. Physiol. Res. 52(3): 299-309. PMID: 12790761 .

Honzíková, N., Labrova, R., Fiser, B., Maderova, E., Novakova, Z., Zavodna, E., and Semrad, B. 2006a. Influence of age, body mass index, and blood pressure on the carotid intima-media thickness in normotensive and hypertensive patients. Biomed. Tech. (Berl.), 51(4): 159-162. PMID:17061929.

Honzíková, N., Nováková, Z., Závodná, E., Paderová, J., Lokaj, P., Fiser, B., et al. 2006b. Baroreflex sensitivity in children, adolescents, and young adults with essential and white-coat hypertension. Klin. Padiatr. 218(4): 237-242. doi:10.1055/s-2005836596. PMID: 16819707.

Iannuzzi, A., Licenziati, M.R., Acampora, C., Salvatore, V., Auriemma, L., Romano, M.L., et al. 2004. Increased carotid intimamedia thickness and stiffness in obese children. Diabetes Care, 27(10): 2506-2508. doi:10.2337/diacare.27.10.2506. PMID: 15451928 .

Kardos, A., Watterich, G., de Menezes, R., Csanády, M., Casadei, B., and Rudas, L. 2001. Determinants of spontaneous baroreflex sensitivity in a healthy working population. Hypertension, 37(3): 911-916. PMID:11244017.

Krontorádová, K., Honzíková, N., Fiser, B., Nováková, Z., Závodná, E., Hrstková, H., and Honzík, P. 2008. Overweight and decreased baroreflex sensitivity as independent risk factors for hypertension in children, adolescents, and young adults. Physiol. Res. 57(3): 385-391. PMID:17552873.

La Rovere, M.T., Bigger, J.T., Jr., Marcus, F.I., Mortara, A., and Schwartz, P.J. 1998. Baroreflex sensitivity and heart-rate variability in prediction of total cardiac mortality after myocardial infarction: ATRAMI (Autonomic Tone and Reflexes After Myocardial Infarction). Lancet, 351(9101): 478-484. doi:10. 1016/S0140-6736(97)11144-8.

Lábrová, R., Honzíková, N., Maderová, E., Vysocanová, P., Nováková, Z., Závodná, E., et al. 2005. Age-dependent relationship between the carotid intima-media thickness, baroreflex sensitivity, and the inter-beat interval in normotensive and hypertensive subjects. Physiol. Res. 54(6): 593-600. PMID:16351497. 
Laederach-Hofmann, K., Mussgay, L., and Rúddel, H. 2000. Autonomic cardiovascular regulation in obesity. J. Endocrinol. 164(1): 59-66. doi:10.1677/joe.0.1640059. PMID:10607938.

Laitinen, T., Hartikainen, J., Vanninen, E., Niskanen, L., Geelen, G., and Länsimies, E. 1998. Age and gender dependency of baroreflex sensitivity in healthy subjects. J. Appl. Physiol. 84(2): 576-583. PMID:9475868.

Langer, S.Z. 2008. Presynaptic autoreceptors regulating transmitter release. Neurochem. Int. 52(1-2): 26-30. doi:10.1016/j.neuint. 2007.04.031. PMID:17583385.

Lefrandt, J.D., Hoogenberg, K., van Roon, A.M., Dullaart, R.P., Gans, R.O., and Smit, A.J. 1999. Baroreflex sensitivity is depressed in microalbuminuric Type I diabetic patients at rest and during sympathetic manoeuvres. Diabetologia, 42(11): 13451349. doi:10.1007/s001250051448. PMID:10550419.

Levy, M.N. 1997. Neural control of cardiac function. Baillieres Clin. Neurol. 6(2): 227-244. PMID:9483290.

Lobstein, T., Baur, L., Uauy, R., and IASO International Obesity TaskForce. 2004. Obesity in children and young people: a crisis in public health. Obes. Rev. 5(Suppl 1): 4-85. doi:10.1111/j. 1467-789X.2004.00133.x. PMID:15096099.

Lohmeier, T.E., Lohmeier, J.R., Haque, A., and Hildebrandt, D.A. 2000. Baroreflex prevent neurally-induced sodium retention in angiotensin hypertension. Am. J. Physiol. 279: R1437-R1448. PMID:11004014.

Lohmeier, T.E., Hildebrandt, D.A., Warren, S., May, P.J., and Cunningham, J.T. 2005. Recent insights into the interactions between the baroreflex and the kidneys in hypertension. Am. J. Physiol. 288: R828-R836. doi:10.1152/ajpregu.00591.2004. PMID:15793036.

Lohmeier, T.E., Dwyer, T.M., Irwin, E.D., Rossing, M.A., and Kieval, R.S. 2007. Prolonged activation of the baroreflex abolishes obesity-induced hypertension. Hypertension, 49(6): R1307R1314. doi:10.1161/hypertensionaha.107.087874.

Mancia, G., Iannos, J., Jamieson, G.G., Lawrence, R.H., Sharman, P.R., and Ludbrook, J. 1978. Effect of isometric hand-grip exercise on the carotid sinus baroreceptor reflex in man. Clin. Sci. Mol. Med. 54(1): 33-37. PMID:620491.

Matsumoto, T., Miyatsuji, A., Miyawaki, T., Yanagimoto, Y., and Moritani, T. 2003. Potential association between endogenous leptin and sympatho-vagal activities in young obese Japanese women. Am. J. Hum. Biol. 15(1): 8-15. doi:10.1002/ajhb. 10111. PMID: 12552573.

Miller, A.W., Sims, J.J., Canavan, A., Hsu, T., and Ujhelyi, M.R. 1999. Impaired vagal reflex activity in insulin-resistant rats. J. Cardiovasc. Pharmacol. 33(5): 698-702. doi:10.1097/00005344199905000-00004. PMID:10226855.

Nagai, N., Matsumoto, T., Kita, H., and Moritani, T. 2003. Autonomic nervous system activity and the state and development of obesity in Japanese school children. Obes. Res. 11(1): 25-32. doi:10.1038/oby.2003.6. PMID:12529482.

Narkiewicz, K., Somers, V.K., Mos, L., Kato, M., Accurso, V., and Palatini, P. 1999. An independent relationship between plasma leptin and heart rate in untreated patients with essential hypertension. J. Hypertens. 17(2): 245-249. doi:10.1097/00004872199917020-00009. PMID:10067794.

Parati, G., Di Rienzo, M., Bertinieri, G., Pomidossi, G., Casadei, R., Groppelli, A., et al. 1988. Evaluation of the baroreceptorheart rate reflex by 24-hour intra-arterial blood pressure monitoring in humans. Hypertension, 12(2): 214-222. PMID: 3410530 .
Persson, P.B., DiRienzo, M., Castiglioni, P., Cerutti, C., Pagani, M., Honzíková, N., et al. 2001. Time versus frequency domain techniques for assessing baroreflex sensitivity. J. Hypertens. 19(10): 1699-1705. doi:10.1097/00004872-200110000-00001. PMID:11593087.

Rocchini, A.P., Moorehead, C., Katch, V., Key, J., and Finta, K.M. 1992. Forearm resistance vessel abnormalities and insulin resistance in obese adolescents. Hypertension, 19(6 Pt 2): 615-620. PMID:1592457.

Spraul, M., Anderson, E.A., Bogardus, C., and Ravussin, E. 1994. Muscle sympathetic nerve activity in response to glucose ingestion. Impact of plasma insulin and body fat. Diabetes, $43(2)$ : 191-196. doi:10.2337/diabetes.43.2.191. PMID:8288042.

Takalo, R., Korhonen, I., Turjanmaa, V., Majahalme, S., Tuomisto, M., and Uusitalo, A. 1994. Short-term variability of blood pressure and heart rate in borderline and mildly hypertensive subjects. Hypertension, 23(1): 18-24. PMID:8282326.

Tanaka, H., Dinenno, F.A., Monahan, K.D., DeSouza, C.A., and Seals, D.R. 2001. Carotid artery wall hypertrophy with age is related to local systolic blood pressure in healthy men. Arterioscler. Thromb. Vasc. Biol. 21(1): 82-87. PMID:11145937.

Tonhajzerova, I., Javorka, M., Trunkvalterova, Z., Chroma, O., Lazarova, Z., Javorkova, J., and Javorka, K. 2006. Comparison of two methods for evaluation of heart rate control in obese children. Acta Med. Mart. 32: 16-21.

Tuck, M.L., Sowers, J., Dornfeld, L., Kledzik, G., and Maxwell, M. 1981. The effect of weight reduction on blood pressure, plasma renin activity, and plasma aldosterone levels in obese patients. N. Engl. J. Med. 304(16): 930-933. PMID:7010165.

Van Vliet, B.N., Hall, J.E., Mizelle, H.L., Montani, J.P., and Smith, M.J., Jr. 1995. Reduced parasympathetic control of heart rate in obese dogs. Am. J. Physiol. 269(2 Pt 2): H629-H637. PMID: 7653627.

Warner, M.R., Senanayake, P.D., Ferrario, C.M., and Levy, M.N. 1991. Sympathetic stimulation-evoked overflow of norepinephrine and neuropeptide Y from the heart. Circ. Res. 69(2): 455465. PMID:1776971.

Wesseling, K.H. 2003. Should baroreflex sensitivity be corrected for heart rate? J. Hypertens. 21(11): 2015-2018. doi:10.1097/ 00004872-200311000-00008. PMID:14597842.

Woo, K.S., Qiao, M., Chook, P., Poon, P.Y., Chan, A.K., Lau, J.T., et al. 2002. Homocysteine, endothelial dysfunction, and coronary artery disease: emerging strategy for secondary prevention. J. Card. Surg. 17(5): 432-435. PMID:12630544.

Yang, T.E., Senturia, J.B., and Levy, M.N. 1994. Antecedent sympathetic stimulation alters time course of chronotropic response to vagal stimulation in dogs. Am. J. Physiol. 266(4 Pt 2): H1339-H1347. PMID:8184912.

Zanchetti, A., Bond, M.G., Hennig, M., Neiss, A., Mancia, G., Dal Palù, C., et al. 1998. Risk factors associated with alterations in carotid intima-media thickness in hypertension: baseline data from the European Lacidipine Study on Atherosclerosis. J. Hypertens. 16(7): 949-961. doi:10.1097/00004872-19981607000008. PMID:9794735.

Zavodna, E., Honzíková, N., Hrstkova, H., Novakova, Z., Moudr, J., Jira, M., and Fiser, B. 2006. Can we detect the development of baroreflex sensitivity in humans between 11 and 20 years of age? Can. J. Physiol. Pharmacol. 84(12): 1275-1283. doi:10. 1139/Y06-060. PMID:17487236. 